\title{
Democratic Transition and Economic Transition: The Case of Tunisia
}

\author{
Samira Kria Chaker \\ University of Carthage, Tunis, Tunisia \\ Laboratory of Economics and Applied Finance (LEAF) (IHEC-Carthage), Tunis, Tunisia \\ IHEC-Carthage, Tunis, Tunisia
}

\begin{abstract}
This paper develops the issue of economic transition linked to a democratic transition that a developing country, Tunisia, is living following the revolution of 2011. Tunisia has made a profound change, it is currently developing new institutions, however, it is not an annuitant country, its activities and economic performances depend on political stability and the choice of the implemented politico-economic system. The question is whether the operating political forces will affect the direction of structural changes, thus toward a transition of breakage or the direction of adaptive transition. Neo-liberalism, practiced for 30 years, has developed an entrepreneurship structured as small and medium enterprises, whose performances are variable according to the sector and the state role. With the revolution, the country entered in a phase of political, social, and economic instability. A new constitution is passed, the political system installs the multiparty system, the country has a tradition of openness to the rest of the world, the challenges are numerous and the question of the role of the state in the economic sphere is very acute. The analysis is based on the observation of facts and the review and analysis of data relating to politics and economy, observed in the period before the revolution and after the revolution.
\end{abstract}

Keywords: democratic transition, economic transition, economic performance, developing countries

In the democratic Tunisia, which begins to be shaped, in the prevailing alchemy, which emits such strong claims of social and economic equity as a yearning for political freedom and alternation in the exercise of power, the question of the economic transition is placed in the spotlight. In effect, there is a major preoccupation of the future of the economic situation in Tunisia, the concern for the moment is to know what is the most appropriate system in these times of institutional and policy reform.

The economic performances are to this day in a very poor shape, the people live in a level of low growth, a state of agitation, all-out claims, a social unrest which can be understood by the eagerness for a job so awaited, a better distribution of wealth especially by those who have been too long ignored. Certainly, Tunisia is living a profound change, it is in the process of developing new institutions, however, this is not an annuitant country, its economic activities are dependent on a political stability, on the security of citizens, on the relationship developed with its partners, on an extrovert system of production, and on the consuming desire of all stakeholders. Therefore, it has to work to satisfy the social aspirations of its population.

Corresponding author: Samira Kria Chaker, Ph.D., professor, Director of Department of Economics, IHEC (Higher Institute for Commercial Studies), University of Carthage, Tunisia; research fields: economic politics, international economics, and Marco economics. E-mail: samira_chaker@yahoo.fr. 
To support only the political claim that the middle class holds and forgets that of justice and of socio-economic equality that the underprivileged classes hold, will lead to serious disappointments. The situation facing Tunisia is born of a mixture of greed, complexity, and bad strategic choices, mainly the strengthening of the regional gap, a marked down educational policy, and a poor use of the available human capital.

The problem of graduates' unemployment can be explained by several factors both in terms of supply and demand in the labor market, however, the phenomenon may be apprehended also via the role played by the educational policy. Has this last played its full role in preparing young people for the labor market or has it failed in its mission?

In the educational system of the last 20 years, two speeds coexist, one concerning an elite drawing its strength from the existence of a middle class that strives at the expense of many sacrifices so that their offspring have the best training, and the other affects a more significant portion of the population, delivered to itself, satisfied with a minimum of supervision, where the training paths are devoid of imagination (the number of faculties training in management in the country is significant) and suffering the vagaries of a depleted educational system, where a high level of the score of success, especially in baccalaureate, is used as a means of propaganda and hypnosis of the society. At the end of the account, the diplomas issued are devalued and inadequate with the labor market.

The wave of neo-liberalism practiced in Tunisia for some 30 years has facilitated the development of an entrepreneurship that depending on the sector of activity, the performances are variables, structured essentially in the form of small and medium enterprises (SMEs), taking advantage in the first place of a protectionism, assuring it a market, certainly, reduced but without foreign competition, then hard hit by the opening of the market and international competition, posing the problem of its competitiveness and undergoing an informal market, destabilizing the local market, under the protection of an oligarchy. This last, taking advantage of a corrupt and criminal political system, has taken over the privatized firms, establishing itself as main actor of the land speculation and the development of the banking and financial system.

In addition, the withdrawal of the state from the economy, marked by a sharp reduction of investment expenditures in a concern of budgetary balance, has not been followed by an increase in private investment. The latter was supposed to create new productive jobs as balancer against the loss of jobs in the public sector and to cope with the increase of young people arriving in the labor market. The rural world has been totally neglected and the liberalization of trade has rendered more difficult than the development of the agri-food and an industry that is creative of skilled jobs.

Thus, the context people live today offers us the opportunity to expose our strengths and weaknesses in order to straighten the country by avoiding the mistakes of the past and capitalizing on what was achieved. The question that arises with acuteness is also the question of whether the political forces present will affect them in the direction of structural changes, therefore are people going toward a transition of breakage or in the direction of an adaptive transition? In the public debate, we often hear about a system that can be characterized as "center", do we meant by that, a mixed system where coexists free initiative and the regulating and effective role of the state? Do we need a shock therapy or gradualism? Citing the case of the countries of Eastern Europe in their transition to a market economy, Andrieff (2007) speaks of a presentation according to a ranking: (1) management of the systemic crisis; (2) destruction of the old system; and (3) building of a new system. For him, there is no contradiction between shock therapy and gradualism to manage a crisis situation, in fact, it is the 
speed in the stabilization and restructuring that is under debate.

\section{Revolution Means Recession}

The revolution of 2011 has plunged the country into a violent recession. Within a year, the growth of GDP (Gross Domestic Product) has collapsed by nearly 2\%, while it stood at around 3\% a year earlier (Central Bank of Tunisia [BCT], 2010-2012). The revolution has caused a paralysis to many productive sectors, including the tourism sector, which is vital for the country which has seen its revenues drop, plunging the mining and petroleum activities, driving away foreign investors. The direct foreign investment has tumbled by $26 \%$.

Added to this is the impact of the situation in Libya which has also known a reversal of its political regime, second trading partner and provider of funds through the Tunisian workers installed in Libya.

Certainly, there is no wonder that the revolution has caused disturbances on the economic plan, in contrast more worrying is the transition, the political uncertainty and the extreme slowness with which the new leaders respond to the emergency situation, including the social claims and source of the revolt.

Reconnecting with the growth is essential, but the political and social context, the climate of insecurity, most of the legacy left by the ousted regime, constitute a set of factors of blocking.

For decades, Tunisia, good student of international institutions, has endeavored to produce a strong and stable growth, 5\% on average per year in constant terms, between 1986 and 2010, conducted without worries of being shared, digging social and regional inequalities. In fact, it was a fuelled growth, behind which were hiding many structural imbalances.

Still today, the final demand is a fundamental component of the economic growth, in spite of a trade balance structurally in deficit. It represents nearly $80 \%$ of the Tunisian GDP, more than $60 \%$ being of private consumption, $20 \%$ being of public. The gross fixed capital formation, that is the accumulation necessary to self-sustained growth, occupies only a low share of this final request. As to the trade balance, it is an impediment to GDP growth, because it is in permanent deficit.

The interventionism of the state in the affairs has created an economy with two speeds. Some sectors are blessed by the state, others are neglected. The vital sectors such as agriculture and the fishing industry have fallen into disuse over the past 10 years, with a low contribution to the increase of wealth.

The market activities have been favored, with in head, the offshore activities with low added value, however oriented toward export, generators of foreign exchange.

According to the Central Bank of Tunisia (BCT), the GDP by sector in 2010 breaks down as follows: $45.5 \%$ for the services; $15.6 \%$ for the non-manufacturing industries; $11 \%$ for the agriculture and fisheries, $16.7 \%$ for manufacturing industries, and $11.2 \%$ for other.

This dualistic structure has an impact on migratory flows, causing sectorial and regional disparities, widening the economic and social divide between the foreshore of the country and the interior region.

In front of this context, what change will the democratic transition lead the economic system to?

\section{What Role Should Be Assigned to the Market and to the State}

Formerly, the conservatives could invoke the invisible hand of Adam Smith, the idea that the markets and the search of the personal interest would be leading, as if they are carried out by an invisible hand, to economic efficiency.

Even if they did admit that the markets may not lead on their own to a distribution of income socially 
acceptable, they argued that the issues of effectiveness should be separated from those related to equity.

From this same point, economic science, attached to effectiveness, equity issues must be left to the politics.

Today, the intellectual defense of the fanaticism of the market has become blurred. Many research projects, including those of Stiglitz (2006) and others, on the economic theory of information, have shown that every time the information is imperfect, in particular when there are asymmetries of information-when some know something that the others ignore (in other words always), the invisible hand is invisible for the good reason that it does not exist!

Without regulations and appropriate interventions of the state, markets do not lead to economic efficiency.

In recent years, and with the current crisis, the author has the spectacular illustrations of these theoretical ideas.

The consequences of the imperfect and limited information, and of the imperfect competition make us conscious of the limits of the market. It is thus necessary to be aware of the need for balance between the state and the market, because the theory according to which only the market is capable of driving to the economic efficiency is flawed in depth, especially in the developing and transition countries (Richter, 2009). The passions raised by the global financial crisis have strengthened the awareness concerning the hazardous nature of the unhindered movement of speculative capital flows. Similarly, the search for the personal interest of the CEOs (Chief Executive Officers), the accountants and business banks, has not led to economic efficiency but to a speculative bubble, accompanied by a massive allocation of unbalanced investment. And when the bubble burst, it has led to the recession, which panics the world today.

The question, which remains, is to know what consequences to draw?

Two theses are present:

(1) The one which favors the thesis of the disorder, of the drift of a system that should be corrected by making call first for the responsibility spirit, for professional ethics and staff of actors of the market, and advocates the establishment of a few reforms, which allow supervision;

(2) On the contrary, the reading of the school of the regulation favors the thesis of inefficient markets and of the systemic crisis. They incite us to reconsider the deregulation.

The first attitude is over-timid, the crisis can withstand the conventional therapies.

The second led to the question the economic and financial globalization and the benefits of the development of an industry of risk management.

Finally, one realizes also, more and more, that there is not a single form of capitalism, and a good way to manage the economy. Advocating a fair balance between the private sector and the public sector, promoting policies capable of making the equality and the full employment progress, leads to an intellectual consistency in compliance with the scientific research.

\section{Free Initiative, Liberalism, and Social Phenomena}

There is a certain belief according to which liberalism would be the cause of poverty and regional imbalances. It is a political sophism deployed very often with demagogic and election-focused ulterior motives.

In reality, liberalism has allowed in many cases an improvement of the quality of life, of the comfort of the populations, of collective services that can be offered to them. The harm of liberalism is more related to the excesses of this doctrine in the economy that is called in the socialist doctrines capitalism or even imperialism. Denounced sometimes rightly, these "products" of liberalism have been progressively supervised and regulated 
in many societies.

The derivatives have stirred great emotion and most of the constitutions have attempted to limit them by the consecration of basic economic rights. Thus, in France, the economic and social rights are contained in the preamble of the constitution of 1946, and which is an integral part of positive law since the preamble of the constitution of the October 4, 1958, refers to it specifically. These principles of economic policy are necessary in the present context, at a time when a new constitution is being prepared for Tunisia.

Today, liberalism:

Does not deny to the state, neither the responsibility to maintain the overall balances, nor the right to finance by the tax services that are offered free to the public, nor the duty to change through the tax system or the social regulations the spontaneous distribution of income, nor the obligation to intervene to promote an industrial indispensable sector, or the development of other sectors, to slow or mitigate human impacts of the changes imposed by the technical progress. (Aron, 1987)

The liberal order requires men adapted to its requirements, at the same time that the institutions which consolidate it, protect it against itself and against its enemies. A market economy requires the protection of the laws, which establish the rules of the competition, prevent fraud, sanction the abuse, protect the vanquished, and restrict the arrogance of the winners. In the last analysis, in the present era, there is an affinity between all forms of liberalism: economic, political, intellectual, and moral.

\section{Conclusions}

This being so, it is up to us, Tunisians create a new system based on a liberalism adapted to the needs and specificities of the country, open to the world, favorable to the traditions of partnership that the country has succeeded to build despite the constraints. However, people should not lose sight of the fundamentals, which are unwavering: Based on the initiative, the responsibility, the good governance, the virtues, which allow the development of the human person. The potential is there, and the task is urgent.

The role of the state should be the result of a democratic negotiation where all political forces adhere to change. Indeed, the overall character of a transformation project requires a series of sequenced reforms, giving priority to the reform of the instrument, i.e., the administration. The transition period is subject to politics that are not working, poorly coordinated, and generating confusion. Successive provisional governments have soon realized, as highlighted Vircoulon (2006), that ruling became the art of managing simultaneous disharmony.

To improve the economic growth is a priority for Tunisia. But growth alone is not sufficient. The alternative growth/decline is wrong, because some activities must grow and others decline to vary degrees depending on the level of development of the various countries of the world (Jackson, 2010). This is probably about putting in place mechanisms for inclusion, upstream, and downstream of the growth process.

An inclusive growth must be based on policies of equal opportunities and access to opportunities (education, health, access to markets for goods and services, credit, and employment). The inclusion also flows by policies of appropriate redistributions, which ensures both fairness in the allocation of public expenditure and in the sharing of the tax burden.

Undeniably, the state has a crucial role to play in terms of the provision of public services, of equal opportunity, and of regulation. The state should promote research and development and support innovation.

Among the developed countries, the case of Sweden is edifying, growth has remained tight, because society benefits from better health, and education systems, where there is less inequality and this is thanks to a 
balanced state market.

\section{References}

Andrieff, W. (2007). Economics of transition. Paris, France.

Aron, R. (1987). Democracy and totalitarianism. Paris, France.

Central Bank of Tunisia (BCT). (2010-2012). Report of the Central Bank of Tunisia. Tunis, Tunisia.

Jackson, T. (2010). Prosperity without growth: The transition to a sustainable economy. Brussels, Belgium.

Richter, S. (2009, March). Central Europe: Economic transition. Foreign Policy Magazine, 489. Retrieved from www.cairn.info/revue

Stiglitz, J. E. (2006). Making globalization work. New York: W W Norton \& Co Ltd.

Vircoulon, T. (2006). From transition to transformation: Understanding the democratic South Africa. Journal of Africanists. Retrieved from http://africanistes.revues.org/869 